\title{
Devir criançando na invenção de outras metodologias (s)em pesquisas em educação
}

\author{
Becoming-child in the invention of other methodologies with(out) educational research
}

Devenir-niño en la invención de otras metodologías si/en investigación educativa

Elenise Cristina Pires Andrade - Universidade Estadual de Feira de Santana | Departamento de Educação | Feira de Santana | BA | Brasil. E-mail: nisebara@gmail.com | (1) orci

Vívian Carla Reis Nery - Secretaria Municipal de Educação de Feira de Santana | Professora | Feira de Santana | BA | Brasil. E-mail: vcnery@gmail.com | (1) orcis

Joana Frank Imbassay - Universidade Estadual de Feira de Santana | Departamento de Educação | Feira de Santana |BA | Brasil. E-mail: joana.frank@gmail.com | Đorcio

Resumo: Pretendemos, com esse texto, abrirmo-nos à invasão de um movimento maquínico: criançar devindo. Devir, em uma vontade de fissurar as lógicas estruturantes tanto das pesquisas e $(m)$ educação quanto no que se refere às escolhas epistemológicas e metodológicas. Imagens $\mathrm{e}(\mathrm{m})$ infâncias como gestos de resistência à captura e formatação do pensamento, efemeridade intensiva ao Aion a nos proporcionar o movimento 'gerúndio' de rizoma na/através das pesquisas (s)em educação. Quais (des)afetos ao texto, às ideias, ao tempo aiônico, às imagens fotográficas um devir-criança pode fissurar nos movimentos performáticos sensíveis e(m) educação? Propomos, então, algumas provocações, novos trajetos metodológicos, invenções que não apenas deem espaço para os diferentes agenciamentos, mas que os reconheçam como elementos para (des)construções do conhecimento assim como de suas expressões. Possibilidades de um criançar, em que potentes invenções experimentais optam pelos entre meios de tempos a estimularem a inventividade criativa.

Palavras-chave: Infância. Metodologia de pesquisa. Imagem.

Abstract: This paper consists of fragments from researches in/with childhood and it proposes a becoming-child to think about methodological and epistemological concerns. This becoming can be seen in the text through images and childhoods as gestures of resistance to the thought's capture and formatting. The aim here is not to ilustrate or to explain nor, even, to justify the choices in a educational research, but to present some questions: What can a becomig-child do when it has been walked through research representation's walls? We propose, then, some provocations and new methodological paths, as well as inventions to differents agencies. This text draw up a (de)constructed machinery (taken as a device) for the possibilities of a becoming-child invasion wthitout/within education.

Keywords: Childhood. Research Methodology. Image.

\footnotetext{
- Recebido em 20 de novembro de 2019 • Aprovado em 21 de junho de 2020 • e-ISSN: 2177-5796
}

DOI: http://dx.doi.org/10.22483/2177-5796.2020v22n2p473-492

Copyright @ 2019. Conteúdo de acesso aberto, distribuído sob os termos da Licença Internaonal da CreativeCommons - CC BY-NC-SA Atribuição Não Comercial (https://br.creativecommons.org/licencas/) - Permite distribuição e reprodução, desde que atribuam os devido créditos à publicação, ao autor(es) e que licenciem as novas criações sob termos idênticos. 
ANDRADE, Elenise Cristina Pires; NERY, Vívian Carla Reis; IMBASSAY, Joana Frank. Devir criançando na invenção de outras metodologias (s)em pesquisas em educação.

Resumen: Este documento consta de fragmentos de investigaciones en / con la infancia y propone un devenir-niño para pensar sobre los aspectos metodológicos y epistemológicos. Este texto puede verse a través de las imágenes y la infancia como gestos de resistencia a la captura y el formato del pensamiento. El objetivo aquí no es ilustrarlo para explicar ni, incluso, justificar las elecciones en una investigación educativa, sino presentar algunas preguntas: ¿Lo qué puede un devenir-niño cuando se lo ha recorrido por los muros de la representación de la investigación educativa? Proponemos, entonces, algunas provocaciones y nuevos caminos metodológicos, así como inventos a diferentes agenciamientos. Este texto prepara una maquinaria (des) construida tomada como un dispositivo para las posibilidades de una invasión de convertirse en niño $\sin /$ dentro de la educación.

Palabras clave: Infancia. Metodología de investigación. Imagen. 


\section{Criança-r}

Criança: criar + -ança; ver cria-; f.hist. sXIII criança no sentido de 'criação', sXIV criança no sentido de 'ser humano', sXIV criança no sentido de 'cria', sXV cryamça no sentido de 'ser humano', nos apresenta o Dicionário Houaiss [...] Criança, criação e $(m)$ dança [...] (Houaiss, 2019).

Figura 1 - Só em agosto? Um coala

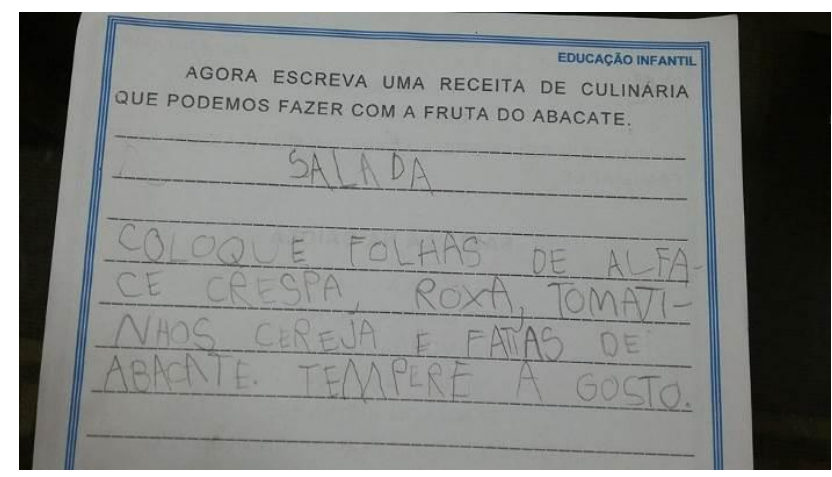

Kaluana Bertoluci Bryan, 21 de setembro de 2016.

Clara escrevendo uma receita para a escola. De repente, peço pra ela escrever "tempere a gosto". Ela me olha e pergunta:

- Tá bom. Mas porque só em agosto?

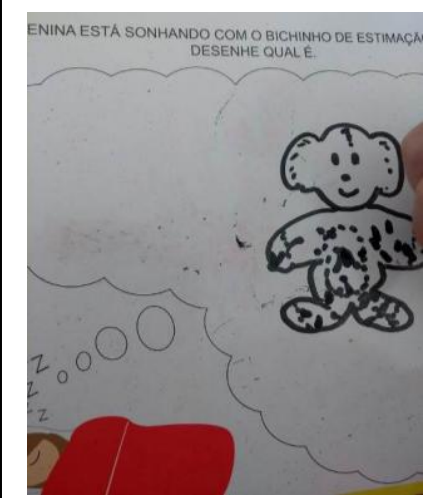

Janaína Garcia, 25 de novembro de 2017.

_ Mãe, desenha um "coala"!

_ Um coala, filho?

_. É, tá escrito aqui: desenhe quale.

\#emLorenzês aos $4 \mathrm{a} 8 \mathrm{~m}$

Fonte: Os depoimentos e as imagens foram obtidas, com o consentimento das mães (Kaluana e Janaína), a partir de das respectivas páginas no perfil do facebook.

Clara e Lorenzo nos convidando a dançar pelo entre tempo do devir em criação. Crianção. Canção que dança como criança grande. Coala? Só em agosto! E rir e criar e dançar e pesquisar e ensinar e aprender. Abrir-se à invasão de um criançar devindo. \#emClarêz, \#emLorenzês. \#emGerundêz. Vindo não se sabe de onde e nem para onde, mas com a vontade de fissurar as lógicas estruturantes das pesquisas e(m) educação, suas/nossas escolhas epistemológicas e metodológicas. Movimentos incessantes de/na produção de conhecimentos que se desprendem de um ciclo abismante de interpretações para, vertiginosamente, surfar através de um entendimento simbólico, como nos apresenta Deleuze e Guattari (2005): 
[...] o entendimento simbólico substitui a analogia de proporção por uma analogia de proporcionalidade; a seriação das semelhanças por uma estrutura das diferenças; a identificação dos termos por uma igualdade das relações; as metamorfoses da imaginação por metáforas no conceito; a grande continuidade natureza-cultura por uma falha profunda que distribui correspondências sem semelhança entre as duas; a imitação de um modelo originário, por uma mimese ela mesma primeira e sem modelo (p. 16-17).

Imagens e(m) infâncias como gestos de resistência à captura e formatação do pensamento, efemeridade intensiva ao Aion que possibilita uma mimese primeira e sem modelo. Entre tempo. Explorar um (des)estabelecimento que fissura a expressão e se movimenta pela escrita acadêmica: nem imagem de infância, nem infância que se estabelece na imagem, mas “[...] pensar a diferença que possa situar a infância numa terra estrangeira afirmativa que coloca em questão a ordem política em vez de colocá-la no campo do receptáculo da formação dos que administram a ordem política estabelecida ou por vir" (KOHAN, 2002, p. 138). A gostos que desenham coalas, bem temperados. Qualé! Potentes invenções experimentais a optarem pelos entre meios de tempos a estimularem a inventividade criativa.

Infância-imagem-gesto dançante, corpo em produção de diferença, de contaminações de mundos impensáveis e expressões quase (im)possíveis. Qualé o tempo do tempero? Um desenho de coala, talvez. Vacúolos de comunicação, já que nada desejam interpretar nem comunicar, mas afecções em acontecimentos. Fragmentos potentes multiplicadores de sentidos e não apenas de explicações dos fatos. Marginalizar os movimentos, permitindo que a ficção teça tanto os processos educativos, como na linda vontade de Amanda Leite (2017), produção, divulgação e expressão de conhecimentos acadêmicos, lidando com o inesperado, "fruir entre conteúdos e sensações, procurar dado novo (dentro e fora da imagem), revelar aos olhos aquilo que não se vê" (p. 30). 
Figura 2 - A mão assopra a fissura
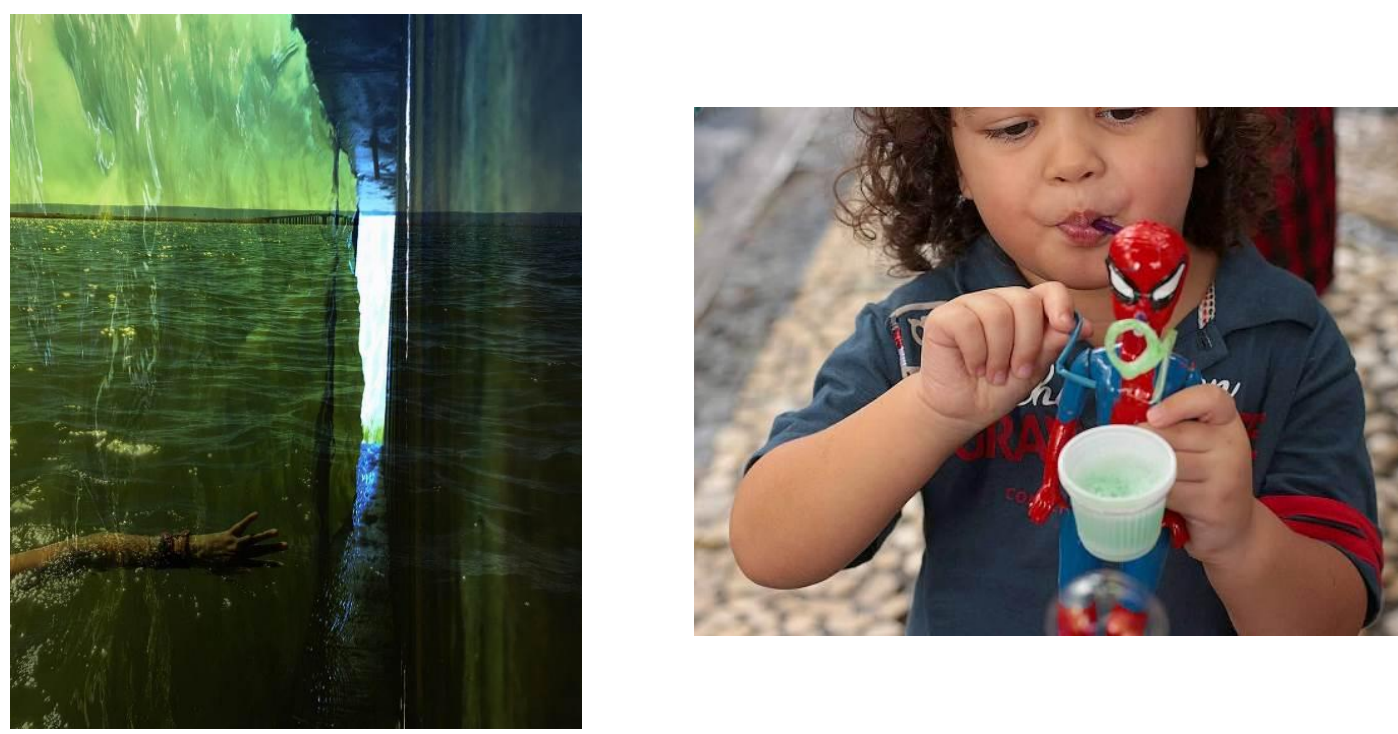

Nota: As imagens foram retiradas dos perfis das autoras do Instagram e contam com a permissão para o uso nesse texto. A imagem da esquerda é de Marli Wunder e a da direita é de autoria de Louise Mara.

Fonte: WUNDER, Marli. Disponível em: https://www.instagram.com/p/BzJYjD-H1H-/. Acesso em: 11 nov. 2019. MARA, Louise. Disponível em: https://www.instagram.com/p/BoOviLXnBfn/. Acesso em: 11 nov. 2019.

Qual é a cor do coala, homem aranha? A gosto das bolhas de sabão, claro, respondeu o vermelho do vestido... Fenda em gesto. Mãos a ondularem os sentidos, os direcionamentos. Um revelar aos olhos que não pretende velar novamente, nem apenas inverter o visível do invisível, o dizível do indizível mas percorrer em linhas derrapantes e intensivas. Criançar, nesse texto, por dois movimentos de pesquisas que atra-versam o campo educação desde dentro de vontades de destravar as portas dos fluxos decorrentes de nossas vivências junto a trabalhos acadêmicos, trazendo as potências desses fluxos que, mesmo sendo planejados e geridos dentro de uma formatação metodológica estudada, concretizada e expressa pelas normas acadêmicas, fraturam uma generalização ditatorial de uma história explicativa e argumentativa única. Escritas, procedimentos metodológicos e estéticos, revisões bibliográficas, pesquisadoras, pesquisadxs em (de)vir. E ir. E vir...

O devir não produz outra coisa senão ele próprio. [...] O que é real é o próprio devir, o bloco do devir, e não os termos supostamente fixos pelos quais passaria aquele que se torna. [...] como um devir não tem sujeito distinto de si mesmo; mas também como ele não tem termo, porque seu termo por sua vez só existe tomado num outro devir do qual ele é o sujeito, e que coexiste, que faz bloco com o primeiro. É o princípio de uma realidade própria ao devir [...] (DELEUZE; GUATTARI, p. 18, 2005). 


\section{0 devir-criançando e a (des)invenção de metodologias de pesquisa em educação}

Abrir espaços para a compreensão do devir-criançando nos contextos que as pesquisas acadêmicas em educação requerem ao pretender, em um primeiro momento, re/des-definir o que compreendemos por método. O cientista social Antonio C. Gil afirma que "pode-se definir método como [o] caminho para se chegar a determinado fim" (GIL, 2008, p. 8). Mas se o devircriançando é processo, inacabado e inacabável, como delimitá-lo enquanto "um fim”? Uma perambulação junto ao devir como conceito chave, como rizoma gerador, demanda uma metodologia de pesquisa plural, fluida, que não apenas acolha os múltiplos caminhos, mas que permita que esses se desenhem.

Se, assim como diziam Freire e Horton (2009), "o caminho se faz caminhando", como seguir caminhos já pavimentados e asfaltados pela lógica acadêmica (fortemente marcada pelo paradigma positivista) para descobrir/percorrer/cartografar territórios subjetivos do devircriançando? Nesta perspectiva, Adriana e César Leite reiteram:

Pesquisar com crianças [...] é não ter um caminho dado, um caminho a priori, mas é se colocar em um caminho porvir, um caminho que ainda não é e quem sabe, que nunca será. Assim, pesquisar não nos parece ser outra coisa que caminhar (LEITE; LEITE, 2014, p. 84, grifo dos autores).

Neste sentido, (des)inventar novas metodologias de pesquisa (s)em educação, partindo do espectro do devir-criançando, implica não apenas romper com o paradigma positivista, mas também, e talvez principalmente, romper com a lógica aca(ba)dêmica. Isto é, desprender-se da ideia de pesquisa e/ou da escrita apenas como objeto final de um processo aparentemente calculado, vendo nele uma verdade absoluta com limites bem delineados. O devir-criançando convida a perceber a pesquisa e as escritas decorrentes dela também como processo, como devir, como algo inacabado, em constante transformação. Vale ressaltar que essa (des)invenção de caminhos não se baseia em um caminhar às cegas, sem rigor metodológico. Longe disso. Significa vivenciar a (des)construção do conhecimento de forma rizomática, possibilitando visibilidades a seus múltiplos caminhos e movimentos.

$\mathrm{Na}$ perspectiva pós-estruturalista, “[...] o rizoma funciona através de encontros e agenciamentos, de uma verdadeira cartografia das multiplicidades. O rizoma é a cartografia, o mapa das multiplicidades" (HAESBART; BRUCE, 2002, p. 4). O próprio devir-criançando, 
enquanto força intensiva, se (des)constrói como rizoma, de forma que constitui territórios plurais, com inúmeras entradas e saídas possíveis, interagindo com diferentes agenciamentos (família, mídia, escola, educação, arte, entre tantos) para eternamente (des)territorizalizar-se (des)construir-se. Neste sentido, a (des)invenção de metodologias, e talvez mais especificamente de métodos-rizoma, se pauta na abertura de novos caminhos que possibilitem uma nova relação com a (des)construção do conhecimento.

Ao propor tal (des)invenção de métodos-rizoma para a pesquisa com/no devir-criançando, vale lembrar, entretanto, o que Virginia Kastrup (2008) nos aponta como um perigoso empecilho enfrentado ao pesquisar territórios que não são nossos (como o da infância, por exemplo):

O maior obstáculo à compreensão das semióticas de um território que não se habita é justamente acreditar que se as compreende. A tradução dos signos em percepções e grades de significação anteriores pode multiplicar a incompreensão, conduzindo aos caminhos do já sabido (KASTRUP, 2008, p. 488).

Sair dos caminhos do já sabido - das pesquisas que iniciam já sabendo seus "resultados" é permitir que os sujeitos do devir-criançando nos mostrem seus (não) territórios, sendo eles pesquisadores ativos, construtores de conhecimento, rompendo, assim, com a lógica do pesquisador que-tudo-sabe e do infans que apenas aprende. Não se trata de "simplesmente" inverter a lógica e estabelecer um novo caminho já sabido, mas sim de manter-se nos contornos, nos (não) limites transitórios dos territórios. Convidamos então xs leitorxs a percorrer alguns dos caminhos (des)inventados para a pesquisa com o devir-criançando.

\section{In(ventos) camufláveis ${ }^{1}$ do devir-CRIAnçar}

O que dirá a folha borrada em versos?

Quem olham?

A arte que des(terra)

De vozes que VERSAM as cores

Potentes dores

Potentes amores

O que dirá a coisa?

Deixar fluir

o ponto da fissura

(Des)travar as portas

Não usar fechaDURAS

\footnotetext{
${ }^{1}$ Quando trouxe o texto-poema acima, quis apresentar a cena camuflável (conceito que aparece na pesquisa por meio de Felipe [de Jesus]), uma performatividade que busca traduzir intersecções dos corpos de vidro que cotidianamente tecem as narrativas da cidade in(visível).
} 
Partindo da cri-AÇÃO que apresenta novas possibilidades às cenas performáticas, os objetos: rosa, botão, pedaço de uma caixa de remédio, plástico, agulha, linha estão sobrepostos nas fotografias a seguir. Essa sobre-posição traz para a cena dermes performaticamente camufláveis em atos de r(e)existências inventivas. Os materiais sensoriais remetem aos "tempos" rizomas de fotos e objetos com novos movimentos (des)montados. São brincadeiras e/ou formas de brincar. Digamos: estamos CRIAnçaANDO! As fotografias/in(ventos) trazem histórias, momentos, emoções, que podem ou não provocar sentidos ao corpo-imagem-leitor. Fluem ao esburacar territórios e emergem à superfície. São camufláveis, ou melhor, in(visíveis) não só aos nossos olhos criativos, mas, ao nosso corpo que anuncia o mergulho líquido sobre as cartografias (des)territorializadas do Aion-CRIAnçar.

Destde modo, vamos escrevinhando sobre as fotos camufláveis do devir-CRIAnçar. Quais in(ventos) trazem à superfície as an(danças) das crianças? Dirá (DELEUZE, 1997, p. 77), “A imagem não é só trajeto, mas devir". Pensando na narrativa que caotiza fotografia/tempo/in(ventos)/camuflagem/CRIAção buscamos (des)terrar algumas imagens performaticamente camufláveis afim de bagunçar um novo, atual, e provocativo sentido ao texto in(certo). "A infância aqui não é apresentada como conceito, ou como referência de um lugar definido e dado, como lugar de uma fase da vida, mas como abertura, como lugar em que a dobra faz surgir outros desdobramentos, outros sentidos" (LEITE, 2015, p. 157).

Transitando sobre as fotografias-infância da pesquisadora Vívian Nery emergimos à superfície os atraVERSAmentos camufláveis. Apresentar esse percurso fluído ao texto é pautar uma discussão sobre dermes in(visíveis) ao que se vê e sente esburacando potências que des(locam), rasgam, borram, desconcertam e provocam multi-triturações nas direções in(certas). Cada fotografia pretende fazer parte de um processo de (des)montagem que cartografa o devircriançar não só da pesquisadora, mas talvez, de um movimento que queira cria-dançar ou cirANDAR. Digamos que essas figuras-sensoriais: “impulsionam para a superfície o camuflável, aquilo que necessita emergir e possibilitar outras leituras da cena clichê" (NERY, 2018, p. 15). 
Figura 3 - Infância rasgada 1

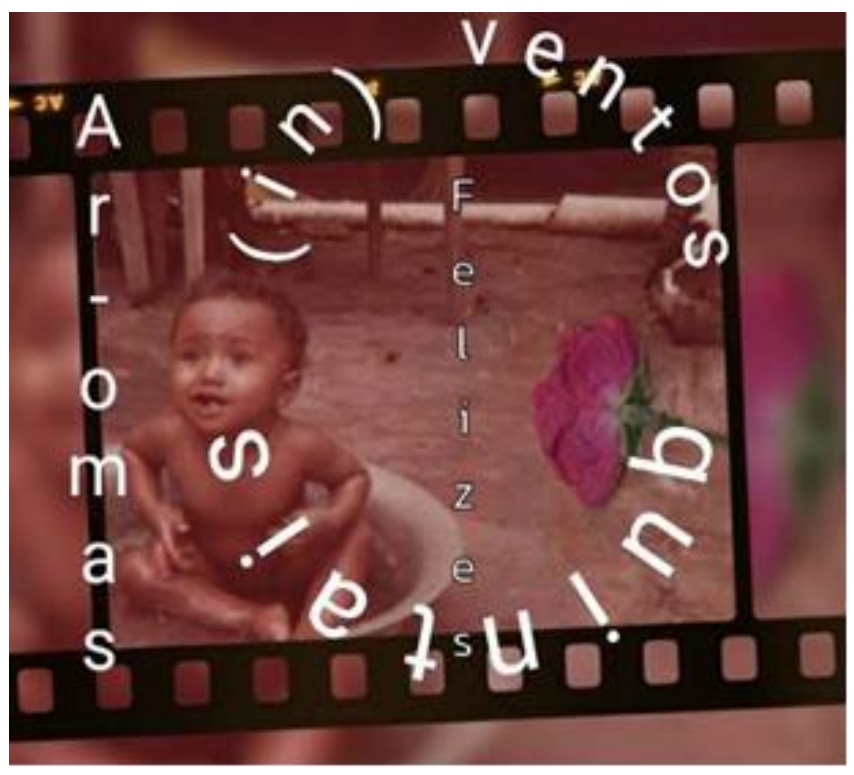

Fonte: Arquivo de Vívian Nery, 1978.

Recortar o sentido e fraturar o texto. Nos quintais se aloja o rasgo-riso latente que cheira uma dimensão CRIAnça. O olfato, a imagem que pulsa e cartografa. Imagens-ação, imagensdireção, imagens que d(e)nunciam resistências potentes, que se relacionam com o ambiente do quintal, da rua, da cidade e da educação. Educações. Imagens que dialogam sobre as diversas infâncias per(vertidas) em devir.

Passo agora por entre os fluxos do dispositivo da memória, assim, relembro do pé de goiabeira da infância, como era inesquecível estar sem camisa e subir naqueles troncos fortes. Ali, se era tudo ou quase nada. Ali, se era gente grande, se era homem, mulher ou qualquer outra coisa. Ali, não havia regras, moldes, fórmulas prontas ou qualquer episódio que buscasse uma direção sobre o que podia ou não. Deste modo, pensando sobre os diversos dispositivos, meus, seus, nossos, gostaria de convidar os leitores a se despirem e viajarem sobre diversos caminhos, para pensar a rua, a escola e nossas histórias sub(versivas) (NERY, 2018, p. 18).

Deixar fluir a imagem, não habitar um lugar e fazer da escrita arte que esburaca o in(visível) na fotografia. O que está camuflavelmente perFORMATizado na fotografia 3? Um banho divertido em um quintal de flores? A mangueira que molha as crianças no sol de primavera na escola? Ou o spray de água e sabão que escorre os vidros dos carros na sinaleira? Tudo está embaralhado na foto da bacia e corpo nu, como possibilidade de 
Ressoar por novas performances, des(configurar) a cena e o ato para emergir o camuflável, como aquele que tece os movimentos da cidade interseccional. Assim, performatividade vira ato que contesta e re(existe), sem a precisão de definir algo ou alguma coisa, apenas como palavra/conceito que esburaca o chão, a fluidez e os cenários desnivelados de sistematização. Evidências de linhas que se diluem, fazendo reascender outras potências (NERY, 2018, p. 45-46).

Infância que permite fissurar uma escrita imprevisível, que vira e (des)vira a potente camuflagem performática. Quais afetos e (des)afetos ao texto, ao leitor e a própria fotografia os materiais que estão sobre-postos nas imagens trazem ao percurso do devir-criança? Quais esburacamentos emergem à superfície procurando desvelar os desdobráveis sentidos das infâncias? Pensamos na possibilidade de um verbo CRIAnçar, no qual as potentes invenções experimentais esburacam os rizomas por entremeio de linhas que estimulam a inventividade criativa dos quintais DEScronológicos.

Figura 4 - Infância rasgada 2
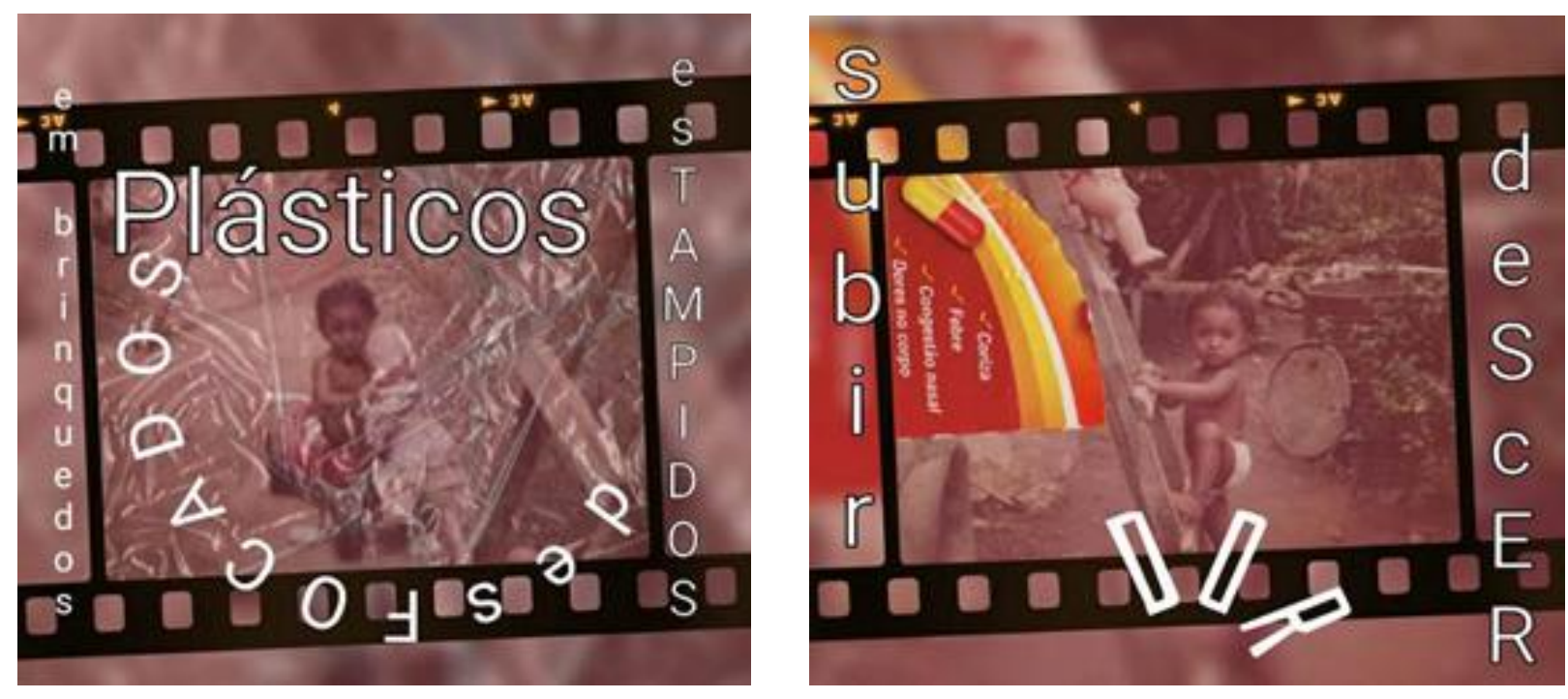

Fonte: Arquivo de Vívian Nery, 1979.

Ver o não visto, permitir o que se vê a não ser visto. Imagens se embaralham, tecem e fissuram os espaços, poetizam a performatividade que des(camufla) a montagem em gestos fragmentos. O plástico abafa a caixa de remédios que re(e)xiste da potente incerteza de pegar uma boneca branca. O território rizomático tece a cena flutuante. Perguntamos: quais brinquedos são permitidos às infâncias? Passear sobre a leveza do quintal e tomar banho no tonel? Qual dor a 
imagem nos provoca? O que está des(focado) na cena? Qual tempo-infância, sentido que desce e sobe permite des(montar) os trapos líquidos da imagem que flutua?

Se a infância é, neste sentido, travessia, percurso, modos de experimentações, na sua relação com a arte e a educação, não importam as "mensagens", "crenças", ideologias que a arte e a educação, possam apresentar, mas, sim, as experiências que elas nos convocam, os afetos que dispara, as sensações que nele e a partir dele acontecem e os sentidos que são produzidos (LEITE, 2015, p. 157).

Cartografar a infância, a pesquisa, as pesquisadoras, xs leitorxs e as próprias imagens rasuradas no texto são parte daquilo do que pode vir a ser. Permitir outros atraVERSAmentos pulsantes, novos olhares, perspectivas singulares e múltiplos sentidos ao texto fragmentado de restos que boiam no tonel que nos banhamos. Desse modo, as imagens carto-foto-grafam as infâncias atraVERSAdas nas andanças ao deixar fluir os rizomas "contra o aprisionamento e a fixidez de sentidos, os essencialismos, o “é isso' ou o 'deve-se fazer assim”” (PARAÍSO, 2014, p. 34).

O camuflável assume uma posição do des(ver) que des(concerta) e emerge até a superfície, onde o próprio conceito aparece. “O camuflável não aborda apenas aquilo que está subtendido, mas o que submerge, o que é expelido das dermes interseccionais" (NERY, 2018, p. 50). Ao trazer as imagens-infância buscamos esse sentido de visão fluída, de superfície rasgada, de montagens e des(montagens) sobre a mesma cena. Será a mesma?

Figura 5 - Infância rasgada 3

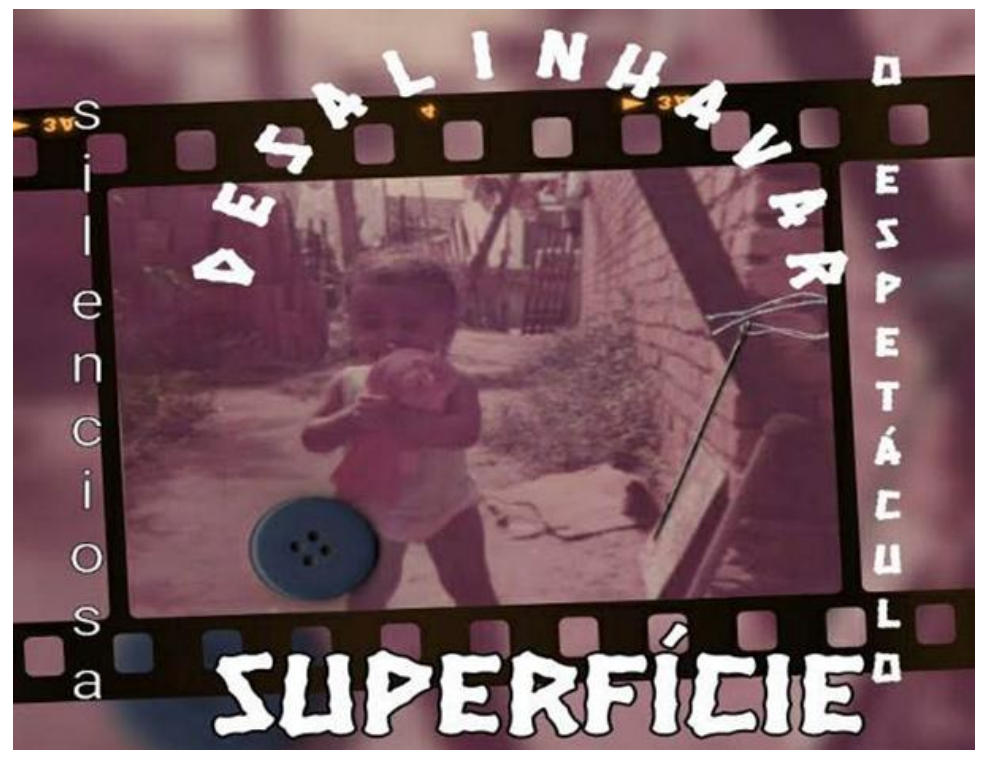

Fonte: Arquivo de Vívian Nery, 1978. 
Alinhavo/educação/infância/corpo. Pegar a agulhar e perfurar o tecido, brincando, visão aguçada, tato descoordenado sobre a superfície camuflável. Aos olhos frouxos, inicio uma costura de uma colcha de retalhos composta de fuxicos sobre quintais das diversas infâncias. Será necessário fazer uso da visão para alinhavar o que emerge a superfície do devir-CRIAnçar?

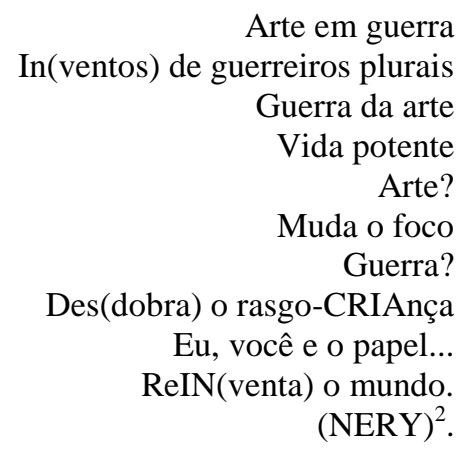

\section{4 (Des)invenções para pesquisar a (des)construção do gênero na Educação Infantil}

A questão da metodologia e da (des)invenção de métodos-rizoma se apresentou no desenvolvimento da pesquisa Ser-estar Mulher: um mapeamento da (des)construção do gênero na educação infantil ${ }^{3}$. A necessidade de pesquisar a (des)construção do gênero na educação infantil, partindo da compreensão dos sujeitos em devir, como movimento (ser-estar mulher, ser-estar criança, etc.), surge de complexos territórios subjetivos que se entrecruzam: o território do serestar professora de crianças pequenas, o de ser-estar mulher em um dos países com maior índice de violência de gênero do mundo ${ }^{4}$, o de ser-estar criança - já/ainda adulta. Surge também em um tempo-espaço de tentativa de silenciamento ao mesmo tempo em que cresce a demanda pela discussão de gênero.

Ainda em andamento, a pesquisa propõe cartografar o território subjetivo que é o gênero, mas especificamente a ideia do ser-estar mulher, em um contexto de Educação Infantil no interior da Bahia. Para tanto, seguindo uma linha pós-estruturalista (fundamentada em autores como

\footnotetext{
${ }^{2}$ Esse texto poético é inédito e está sendo publicado aqui pela primeira vez.

${ }^{3}$ Pesquisa em andamento realizada no Programa de Pós-Graduação em Educação da Universidade Estadual de Feira de Santana - UEFS, pela mestranda Joana Frank Imbassay com orientação da Prof ${ }^{a}$ Dra. Elenise Cristina Pires Andrade.

${ }^{4}$ De acordo com ranking do Alto Comissariado das Nações Unidas para os Direitos Humanos (ACNUDH), o Brasil o ocupa o $5^{\circ}$ lugar mundial em feminicídio, vide lista de referências.
} 
DELEUZE, GUATTARI, 2011; 2012; ROLNIK, 2011; PEREIRA, 2016; FOUCAULT, 2014) a pesquisa parte do pressuposto de que os sujeitos são seres metaestáveis, em eterno devir: não se delimitam a identidades impostas, não concluem o seu processo de tornar-se, são atravessados por diferentes agenciamentos e se (des)territorializam constantemente. Assim, este "mapeamento subjetivo" vem sendo construído não apenas por textos academicamente normatizados, mas também por fotografias feitas pelas próprias crianças - que compõem o seu próprio texto, seu próprio dizer, seu próprio CRIAnçar.

Figura 6 - Registro fixo de um movimento eterno

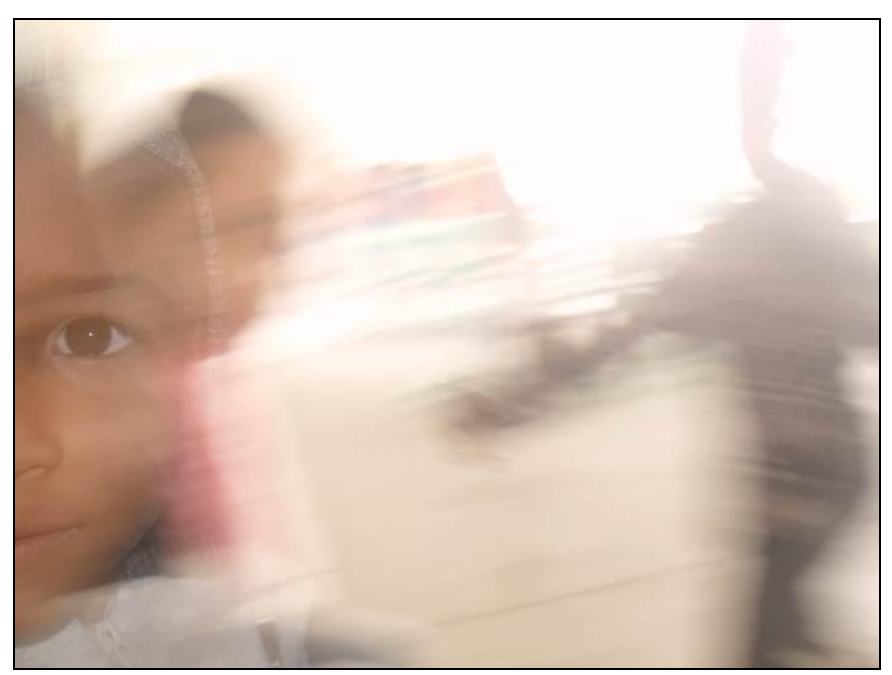

Fonte: Arquivo da pesquisa Ser-estar Mulher.

Por mais que as crianças sejam organizadas na escola pelo critério único da faixa etária, vale ressaltar mais uma vez que a nossa compreensão de infância vai para muito além de um número. Na perspectiva de Paulo Freire, apontada por Walter Kohan (2018), trazemos nesse texto que o devir-criançando

[...] desborda a mais tradicional ideia da infância como etapa cronológica para instaurar uma meninice como força da vida, não apenas para a vida individual de um ser humano em qualquer idade, mas, inclusive, ou, sobretudo, para a vida coletiva, isto é, para uma revolução política (KOHAN, 2018, p. 3).

Para a realização dessa pesquisa (Ser-estar Mulher), propomo-nos a pensar metodologias em um funcionamento rizomático que levassem em consideração essa compreensão de infância, do devir-criançando. De que forma poderíamos escutar as vozes plurais das crianças? Como 
abordar as discussões de gênero com crianças tão pequenas (entre 3 e 6 anos de idade)? Como garantir o espaço para o devir-criançando, sem imobilizá-lo na lógica da escrita e do pensamento aca(ba)dêmico? Dentre inúmeros caminhos que poderiam ser caminhados, optou-se pela abordagem da pesquisa com imagens - neste caso, fotográficas.

A pesquisa com imagens, e por consequência, uma análise e escrita com imagens abrem espaço para atravessamentos outros que um texto "simples" não permitiria. Além disso, como reforçar a importância de se escutar às crianças se elas próprias não se fariam presentes em uma escrita estritamente acadêmica? De acordo com Hernandez (2013), para além de analisar os objetos (as fotografias) em si, o que mais importa seria perceber como tais objetos nos afetam. Isto é, não basta olhar as fotografias, é preciso enxergar quais relações se estabelecem com elas tanto de nossa parte, quanto por parte das crianças. Nesta mesma lógica, César Leite e Bianca Chisté sinalizam que

O que se deve 'ler' nelas [nas imagens] não é o que elas dizem, mas aquilo que elas nos dão a pensar. Por isso, pensar com as imagens, ou pensar além delas, é escuta, é olhar atento, é deslocamento, são outras travessias. Olhá-las, não é criar um campo onde elas estão ali para serem analisadas, interpretadas, mas recolher-se na intimidade daquilo que dá o que pensar. É demorar-se nisso (2015, p. 274).

Figuras 7 a 10 - Olhos que vêem - Olhos que são vistos
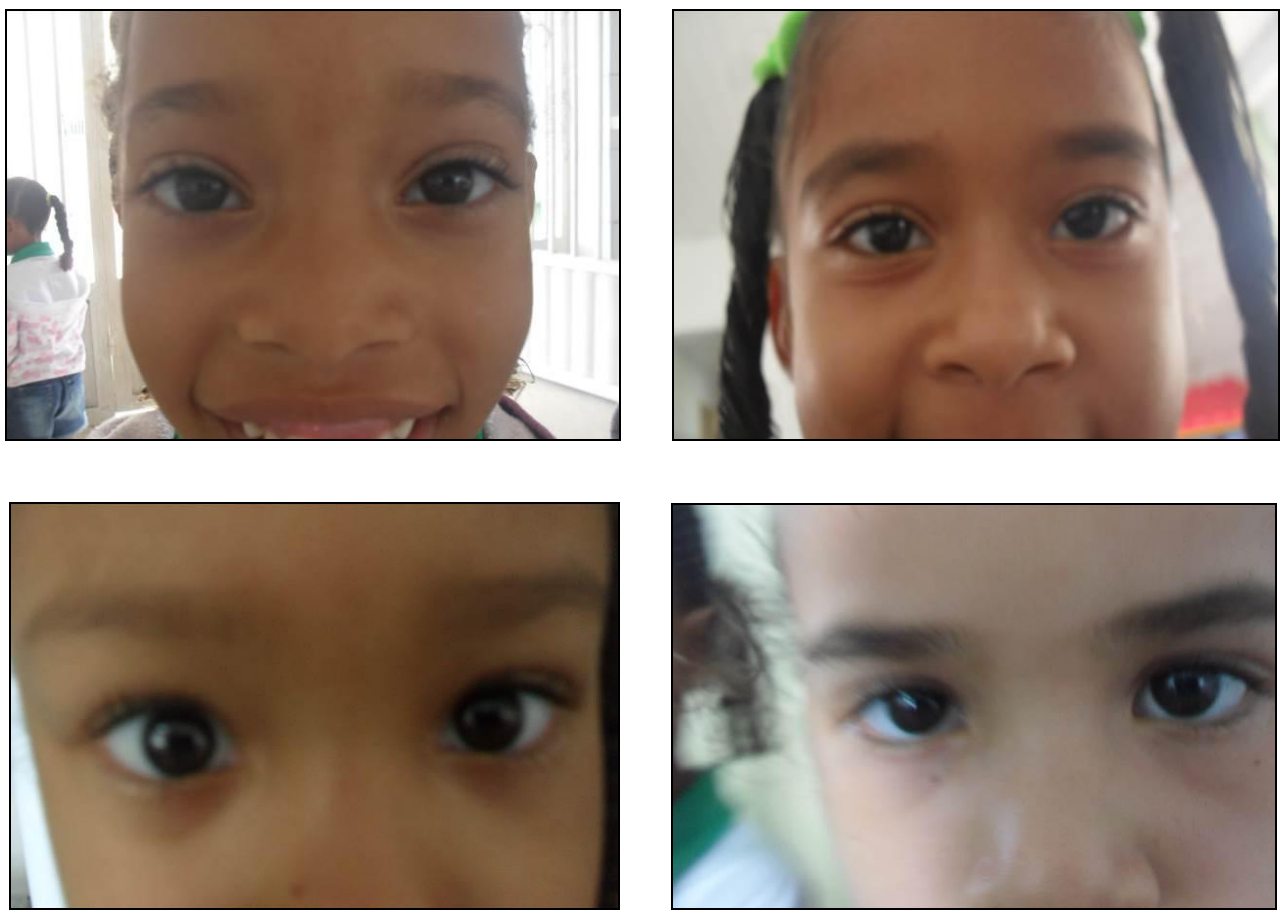

Fonte: Arquivo da pesquisa Ser-estar Mulher. 
As imagens que compõem esta parte do texto foram produzidas pelas crianças após a realização de contações de história - usadas aqui como instrumento de afetação, de deslocamento. Como o intuito da pesquisa é cartografar a (des)construção de gênero na educação infantil, possibilitando assim a entrada desta discussão na escola, as histórias foram minuciosamente escolhidas tendo como critério o rompimento com padrões de gênero, sendo selecionadas histórias infantis que apresentem de forma "não convencional" os papeis culturalmente designados a homens e mulheres. As histórias foram retiradas de duas coletâneas infantis que se propõem justamente à esta discussão, a de romper com preconceitos de gênero: Chapeuzinho Esfarrapado e outros contos feministas do folclore mundial (PHELPS, 2016) e Princesas, Bruxas e uma sardinha na brasa (GOMES; SOUZA, 2017).

Após a contação de história, conversamos "livremente" sobre o que acharam, o que lhes chamou a atenção e aí partimos para as fotografias. As crianças compartilham as 6 câmeras digitais e fotografam pela escola. Fotografam a si mesmos, os espaços - ocupados e proibidos -, os sujeitos que os ocupam, os lugares mais inusitados (que talvez sejam os mais comuns, a depender do ponto de vista).

Figura 11 e 12 - O Comum e o estranho - O estranho e comum
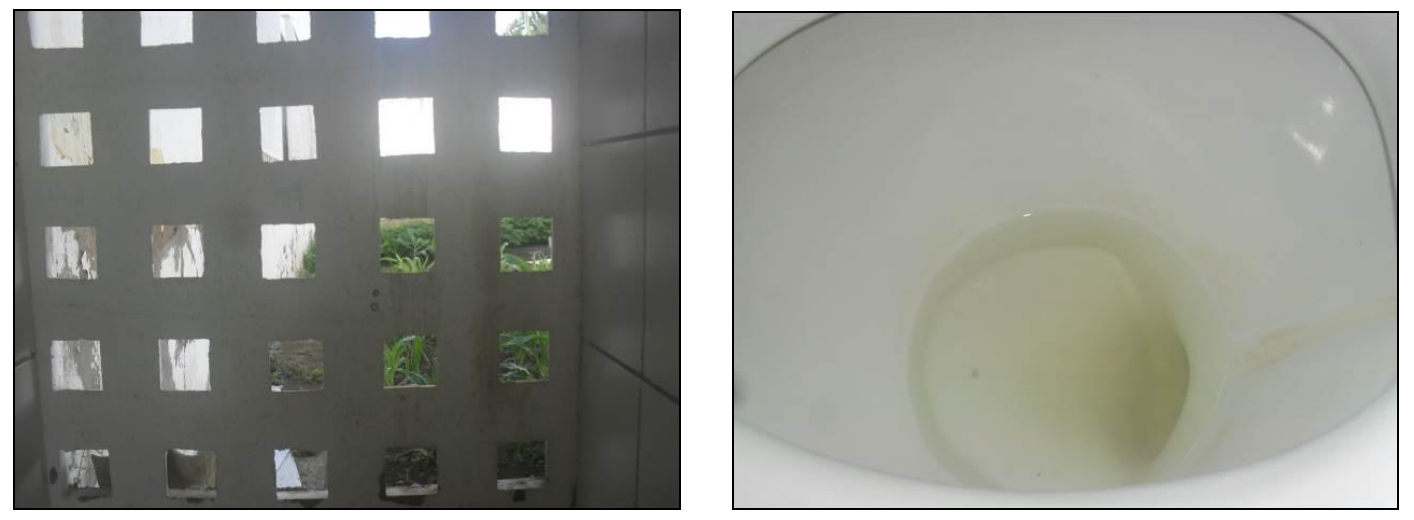

Fonte: Arquivo da pesquisa Ser-estar Mulher.

As fotografias das crianças não servem como ilustração, complemento de um texto escrito, mas compõem elas mesmas outro(s) texto(s), outra(s) narrativa(s). A escolha dos objetos, dos espaços, sujeitos que são fotografados vai delineando de forma expressiva, mas palpável (em formato de imagem) relações que são estabelecidas. As relações dos corpos com os espaços; com os objetos proibidos (colocados estrategicamente em locais mais altos para não serem pegos, mas 
que são admirados de longe); e com os espaços que são de uso comum e corriqueiro, como os banheiros, mas que para um adulto que já imobilizou seu devir-criançando não passa de um espaço de tabu, apontam para essas outras múltiplas narrativas possíveis, que também nos ajudam a pensar o gênero na escola.

Figura 13 - O objeto do desejo proibido. De que serve uma boneca em cima do armário?

Fonte: Arquivo da pesquisa Ser-estar Mulher.

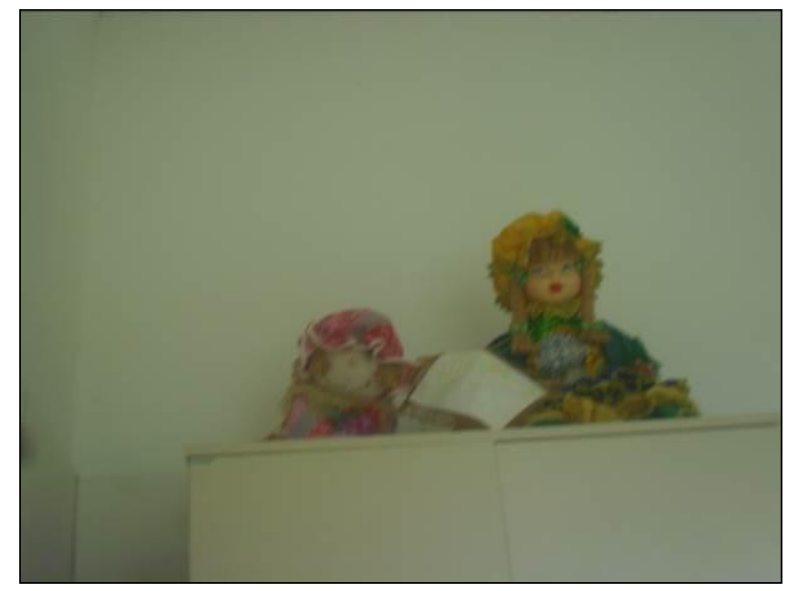

Embora a pesquisa Ser-estar Mulher ainda esteja em fase de conclusão, é possível antecipar que a tomada de uma método-rizoma, a assunção do devir-criançando como movimento intenso que nos desloca, de fato, desestabiliza. Tira do conforto x pesquisadorx, incomoda, causa agonia, e até raiva pela falta de controle, mas finaliza com a sensação do novo. Do caminho que ainda não era sabido, do inesperado. Os corpos das crianças, já tão alinhados e normatizados à lógica da escola, mostram através da fotografia discursos que nas conversas "livres" (mencionadas alguns parágrafos acima) não são possíveis - não possíveis no sentido de não permitidos, não ensinados, não estimulados.

Como já referido antes, as imagens produzidas pelas crianças criaram novos textos, paralelos àquele escrito pela pesquisadora. As fotografias, e talvez ainda os momentos em que estas foram "escritas", nos mostram como as relações são (des)construídas no cotidiano da escola, como mesmo em rotinas fechadas se abrem rachaduras para o devir-criançando, como pelas beiradas se (des)constroem os territórios do gênero e da infância. Mostram, acima de tudo, a infinitude de possibilidades de (des)construção do conhecimento ao lermos o mundo e os sujeitos em rizoma. 
Figura 14 - Outras personagens possíveis.

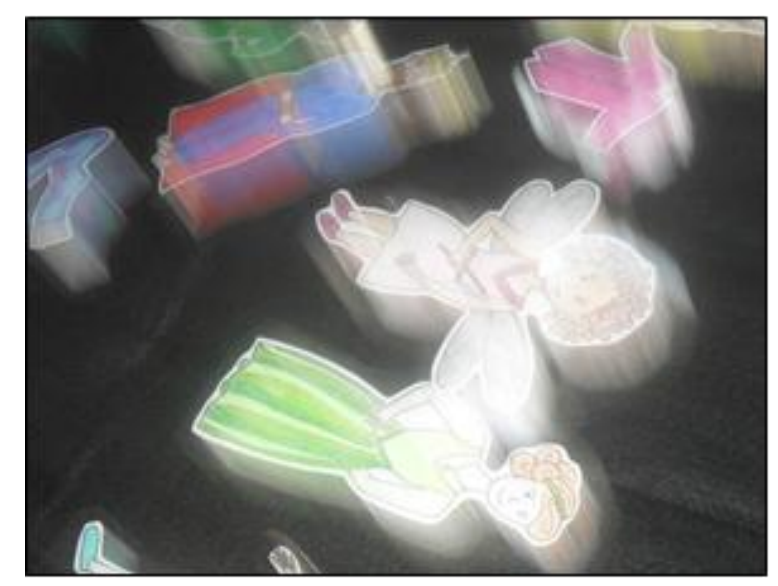

Fonte: Arquivo da pesquisa Ser-estar Mulher.

\section{5 \#emGerundêz}

- Como garantir o espaço para o devir-criançando, sem imobilizá-lo na lógica da escrita e do pensamento aca(ba)dêmico?

- Talvez com a receita da salada a gosto do coala!

- Siiiiiiiiim, com um banho na tina. Agora vamos brincar com a torneira do banheiro da escola?

- Vamos chamar os olhos dos botões, assim conseguimos molhar mais o desenho.

- Da mão que assopra as fissuras?

- Qualé! O do coala que está em cima do armário!

Figura 15 - O que pode uma criança? O que pode um criançar?

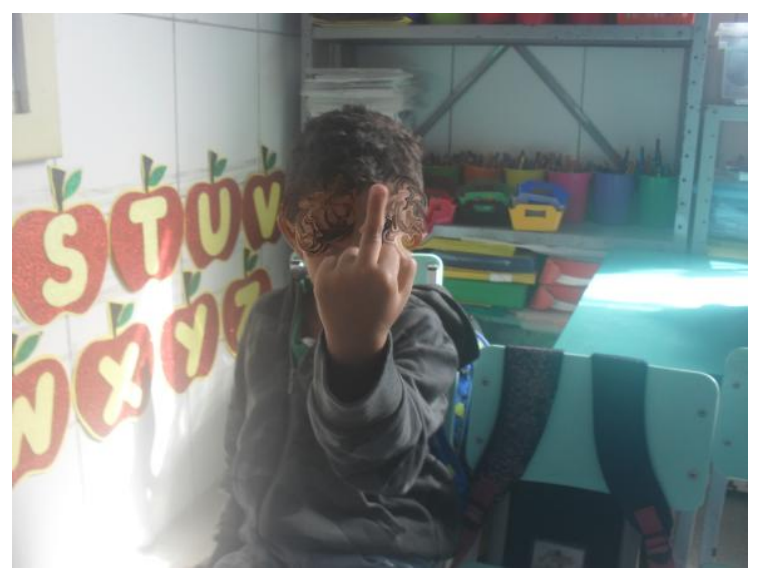

Fonte: Arquivo da pesquisa Ser-estar Mulher. 
Fluxo intensivo que não pretende INverter os movimentos já sistematizados, acordados, fundamentados pelas ações, pensamentos e expressões da produção de conhecimento científico a partir de programas de pós-graduação (especialmente em educação), mas INventar na leveza do sopro, no tempero de agosto, no traço do coala. Qualé, tendeu? Estender o entendimento. Quase um desentender.

Traços, cores, luzes, linhas, contornos em intensidades pelas fotografias, poemas, performances, escritas. Manoel de Barros nos sussurra: "Então era preciso desver o mundo para sair daquele lugar imensamente e sem lado (BARROS, 2013, p. 450)". Que desvisões seriam essas a desviarem das explicações e representações? Adicionemos ainda mais um tempero a essas (im)possibilidades: como tencionar uma metodologia distendida como violência no pensamento a nos provocar a pensar o impensado, traindo os procedimentos de uma escrita de ordem, sempre "em nome de", desenhando procedimentos metodológicos que acolhem o gesto do desmanche, desfiando-a para além do território da interpretação e arrastando o pensar junto a uma metodologia para o fora? Não se trata de levá-la para fora, mas de tentar pensá-la para fora dos territórios estritos da escrita, da sintaxe, dos limites (ROMAGUERA; ANDRADE, 2019, p. 2).

Des-morar. Demorar em percursos improváveis. Devaneios. Ritmos nas linhas dos corpos-crianças-fotografias e dos sentidos e dos conhecimentos. Contornos em desmanche. Ir e vir por pesquisas e escritas que perfuram e subvertem-se em potências outras que não as palavras de ordem, desmoronando as superfícies que pretendem fixar um reconhecimento sobre o pensamento e sobre os tempos-espaços, subvertendo generalizações, fixações, demonstrações, comprovações. Desfiar em desafios os contornos das pesquisas (s)em educação.

\section{Referências}

DELEUZE, Gilles; GUATARI, Félix. Mil Platôs: capitalismo e esquizofrenia. São Paulo: Editora 34, 2005. v. 4.

DELEUZE, Gilles; GUATARI, Félix. Mil Platôs: capitalismo e esquizofrenia. São Paulo: Editora 34, 2011. v. 1.

DELEUZE, Gilles; GUATARI, Félix. Mil Platôs: capitalismo e esquizofrenia 2. 2. ed. São Paulo: Editora 34, 2012. v. 4.

DELEUZE, Gilles. Crítica e clínica. São Paulo: Editora 34, 1997.

DIGA não ao feminicídio. Istoé, São Paulo, 20 jun. 2019. Disponível em: https://istoe.com.br/diga-naoao-feminicidio/. Acesso em: 3 nov. 2019.

FREIRE, Paulo; HORTON, Myles. O caminho se faz caminhando. Rio de Janeiro: Vozes, 2009.

FOUCAULT, Michel. A ordem do discurso: aula inaugural no Collège de France, pronunciada em 2 de dezembro de 1970. 24. ed. São Paulo; Edições Loyola, 2014. 
ANDRADE, Elenise Cristina Pires; NERY, Vívian Carla Reis; IMBASSAY, Joana Frank. Devir criançando na invenção de outras metodologias (s)em pesquisas em educação.

GIL, Antonio Carlos. Métodos e técnicas de pesquisa social. 6. ed. São Paulo: Atlas, 2008.

GOMES, Helena; SOUZA, Geni. Princesas, bruxas e uma sardinha na brasa: contos de fadas para pensar sobre o papel da mulher. São Paulo: Biruta, 2017.

HAESBART, Rogério; BRUCE, Glauco. A desterritorialização na obra de Deleuze e Guattari. Geographia, Niterói, v. 4, n. 7, p. 7-22, 2002.

HOUAISS, Antonio. Dicionário Houaiss Digital. 2019. Disponível em: https://houaiss.uol.com.br/pub/apps/www/v3-3/html/index.php\#2. Acesso em: 11 nov. 2019.

HERNANDEZ, Fernando. Pesquisar com imagens, pesquisar sobre imagens: revelar aquilo que permanece invisível nas pedagogias da cultura visual. In: MARTINS, Raimundo; TOURINHO, Irene. (orgs.). Processos e prática de pesquisa em cultura visual e educação. Santa Maria: Ed. da UFSM, 2013. p. 77-95.

KASTRUP, Virgínia. O método da cartografia e os quatro níveis da pesquisa-intervenção. In: CASTRO, Lúcia Rabello de; BESSET, Vera Lopes. (orgs.). Pesquisa-intervenção na infância e juventude. Rio de Janeiro: Trarepa/FAPERJ, 2008. p. 465-489.

KOHAN, Walter Omar. A cidade da formação. In: GALLO, Sílvio; VEIGA-NETO, Alfredo. (orgs.). Fundamentalismo e educação. Belo Horizonte: Autêntica, 2002. p. 131-144.

KOHAN, Walter Omar. Paulo Freire: outras infâncias para a infância. Educação em Revista, Belo Horizonte, v. 34, p. 1-33, 2018.

LEITE, Amanda M. P. Qual é o lugar da ficção na educação? Leitura: Teoria e Prática, Campinas, v. 35, n. 69, p. 25-35, 2017.

LEITE, César Donizetti Pereira. Pesquisa, arte e educação em modos de encontro: ensaios sobre um "devir arte/ educação para a pesquisa". In: SCARELI. Giovana. (org.). Educação, culturas, políticas e práticas educacionais e suas relações com a pesquisa. Porto Alegre: Sulina, 2015. p. 149-164.

LEITE, César Donizetti Pereira; LEITE, Adriana Regina Isler Pereira. Imagens como epígrafe: imagens lúdicas de experiência infantil. RevistAleph, Niterói, v. 11, n. 22, p. 81-69, dez. 2014.

LEITE, César; CHISTÉ, Bianca. Imagens de crianças: travessias do universo infantil. Educação, Porto Alegre, v. 38, n. 2, p. 272-279. maio/ago. 2015. Disponível em:

http://revistaseletronicas.pucrs.br/ojs/index.php/faced/article/view/17764/13665. Acesso em: 18 jun. 2019.

NERY, Vívian Carla Reis. Espetáculos per(formáticos) abalam as fronteiras da cidade sub(versiva). 2018. 113 f. Dissertação (Mestrado Acadêmico em Educação) - Universidade Estadual de Feira de Santana, Feira de Santana, 2018.

PARAÍSO, M. A. Metodologias de pesquisa pós-críticas em educação e currículo: trajetórias, pressupostos, procedimentos e estratégias analíticas. In: MEYER, D. E.; PARAÍSO, M. A. (org.). Metodologias de pesquisas pós-críticas em educação. 2. ed. Belo Horizonte: Mazza Edições, 2014.

PEREIRA, Marcos Villela. Estética da professoralidade: um estudo crítico sobre a formação do professor. Santa Maria: Ed. da UFSM, 2016.

PHELPS, Ethel Johnston (org.). Chapeuzinho esfarrapado e outros contos feministas do folclore mundial. São Paulo: Seguinte, 2016.

ROLNIK, Suely. Cartografia sentimental: transformações contemporâneas do desejo. Porto Alegre: Sulina, 2011. 
ANDRADE, Elenise Cristina Pires; NERY, Vívian Carla Reis; IMBASSAY, Joana Frank. Devir criançando na invenção de outras metodologias (s)em pesquisas em educação.

ROMAGUERA, Alda R. T.; ANDRADE, Elenise C. P. (Proble)matiz-ar pesquisas e(m) educações: fissuras metodológicas (em via)gem. In: REUNIÃO ANUAL DA ANPEd, 39., 2019, Niterói. Anais [...]. Niterói, RJ: ANPEd , 2019. Disponível em: http://39.reuniao.anped.org.br/wp-

content/uploads/sites/3/trabalhos/4820-TEXTO PROPOSTA COMPLETO.pdf. Acesso em: 11. nov. 2019. 